\title{
Laparoscopic right hepatectomy with selective vascular clamping in an anterior approach manner
}

\author{
Bingfeng Huang", Qida Hü, Risheng Que \\ Department of Hepatobiliary and Pancreatic Surgery, Second Affiliated Hospital, Zhejiang University School of Medicine, Hangzhou 310009 , China \\ \#These authors contributed equally to this work. \\ Correspondence to: Risheng Que. Department of Hepatobiliary and Pancreatic Surgery, Second Affiliated Hospital, Zhejiang University School of \\ Medicine, Hangzhou 310009, China. Email: que@zju.edu.cn.
}

\begin{abstract}
A 39-year-old female patient presented with huge hepatocellular carcinoma (HCC) in the right lobe with clinical stage IIIA (cT3N0M0). Preoperative evaluation indicated the feasibility of a right hepatectomy. A laparoscopic right hepatectomy in an anterior approach was then performed. Selective clamping of the right branch of the portal vein was applied, and the estimated blood loss was $200 \mathrm{~mL}$. Postoperative pathology suggested HCC of Edmondson Grade III and stage IIIA (pT3N0M0).
\end{abstract}

Keywords: Laparoscopic right hepatectomy; selective vascular clamping; hepatocellular carcinoma (HCC)

Submitted Jul 20, 2018. Accepted for publication Aug 01, 2018.

doi: $10.21037 /$ tcr.2018.08.02

View this article at: http://dx.doi.org/10.21037/tcr.2018.08.02

\section{Introduction}

The annual number of laparoscopic hepatectomy cases is rapidly increasing in the recent decade, along with prosperous development of enhanced recovery after surgery (1). Laparoscopic approach has been widely applied in various hepatectomy, from resection of solitary liver cancer to anatomic resection of multiple segments, even colorectal liver metastasis and living donor hepatectomy (2-4). Indications of laparoscopic hepatectomy have gradually broadened, indicating the possibility of laparoscopic approach in nearly all kinds of hepatectomy cases. Comparing to open hepatectomy, laparoscopic approach showed similar oncologic outcomes and operative safety, which has been verified by a large number of studies (5-6). In this report, we present a surgical case of laparoscopic right hepatectomy with selective vascular clamping in an anterior approach for a 39-year-old female patient with hepatocellular carcinoma (HCC).

\section{Surgical technique}

A huge HCC lesion was discovered in the segments VIVII, with two satellite lesions involving segments VIII.
The middle hepatic vein (MHV) was intact. A contrasted magnetic resonance $(\mathrm{MR})$ scan also indicated intratumoral hemorrhage (Figure 1). The multidisciplinary board diagnosed this patient as HCC with clinical stage IIIA (cT3N0M0) according to the $8^{\text {th }}$ edition of AJCC staging system. We planned to perform a laparoscopic right hepatectomy in this patient. Simulated preoperative assessment of postoperative remnant liver function showed that the future liver remnant (FLR) of 521 $\mathrm{cm}^{3}$ and the standard liver volume (SLV) of $1,088 \mathrm{~cm}^{3}$ resulted in a FLR/SLV ratio of $47.89 \%$, indicating the feasibility of right hepatectomy in the patient with the indocyanine green retention rate at $15 \mathrm{~min}$ (ICG R15) of $5.7 \%$ and the total bilirubin level in a normal range.

After laparoscopic exploration, the Calot's triangle was exposed, and the cystic duct and the cystic artery were identified and dissected with Hem-o-lok (Figure 2). The gallbladder was then removed from the cystic plate with cauterization. After the right hepatic artery was dissected with Harmonic scalpel, and ligated with Hem-o-lok, the right branch of the portal vein was clamped with Mersilk suture to block the blood flow to the right lobe (Figure 3). The second hepatic hilum was dissected with Harmonic to expose the suprahepatic inferior vena cava (IVC) and 


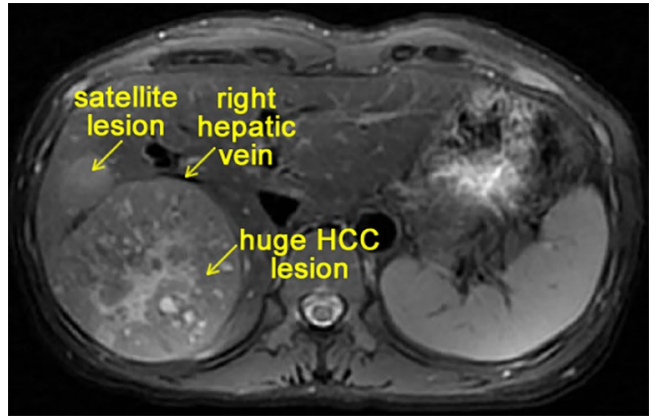

Figure 1 A huge HCC lesion with satellite lesions in a contrasted MR scan. HCC, hepatocellular carcinoma; MR, magnetic resonance.

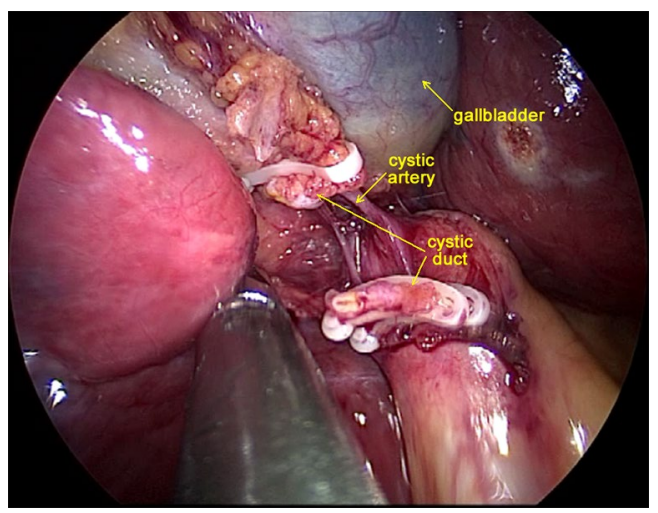

Figure 2 The cystic duct and the cystic artery were identified and dissected with Hem-o-lok.

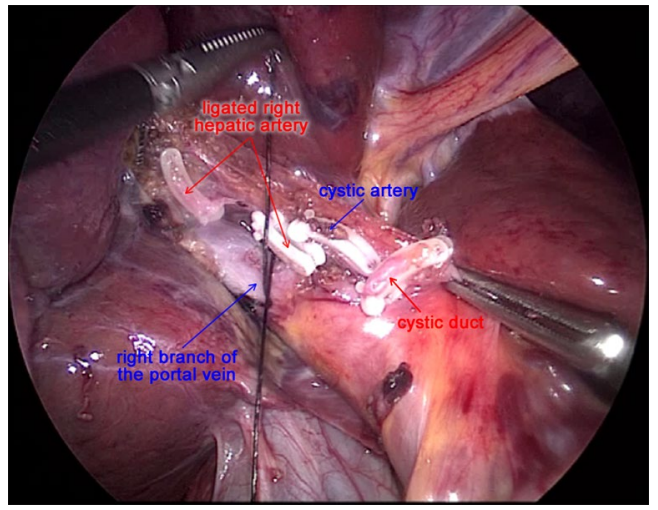

Figure 3 Selective vascular clamping with ligation of the right hepatic artery and the right branch of the portal vein.

the right hepatic vein (RHV) after the hepatic falciform ligament division. The caval ligament was then dissected, where the exposed short hepatic veins (SHVs) were

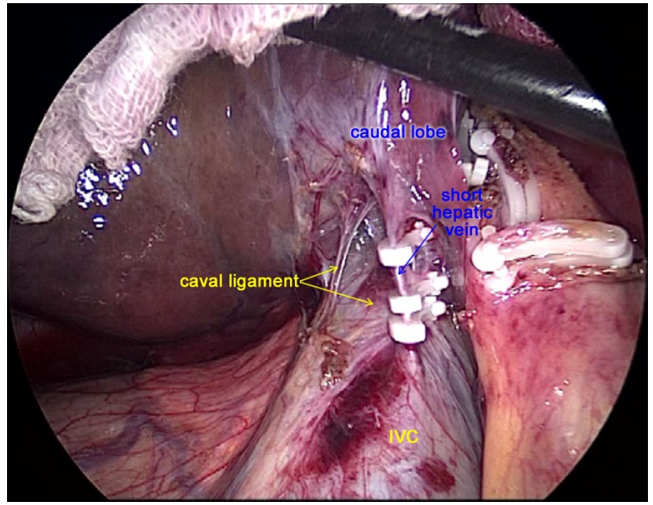

Figure 4 Dissection of the caval ligament with the exposed short hepatic veins carefully ligated.

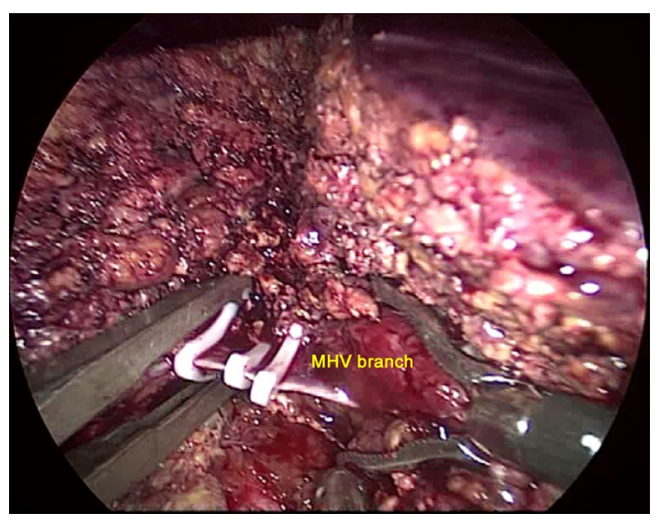

Figure 5 A branch of $\mathrm{MHV}$ was dissected and ligated with Hemo-lok during parenchymal transection. MHV, middle hepatic vein.

carefully ligated (Figure 4). After liver hanging using a 2-0 straight-needle monofilament nylon suture, parenchymal transection was performed with Harmonic according to the Rex-Cantile's line marked with Harmonic. The branches of MHV was dissected and ligated with Harmonic (for the small MHV branches) or Hem-o-lok (Figure 5). After parenchymal transection between the segment IV and segments V/ VIII, the caudal lobe was then dissected along the paracaval parenchyma to expose the right hepatic pedicle with careful dissection of the SHVs, reserving the Spiegel lobe (Figure 6). The right branch of the portal vein and the right Glisson's pedicle were then ligated with an Endo GIA stapler. The Arantius ligament along with the RHV was also staple ligated subsequently (Figure 7). The right lobe was completely mobilized by dissection of the right coronary ligament and right triangular ligament with Harmonic. 


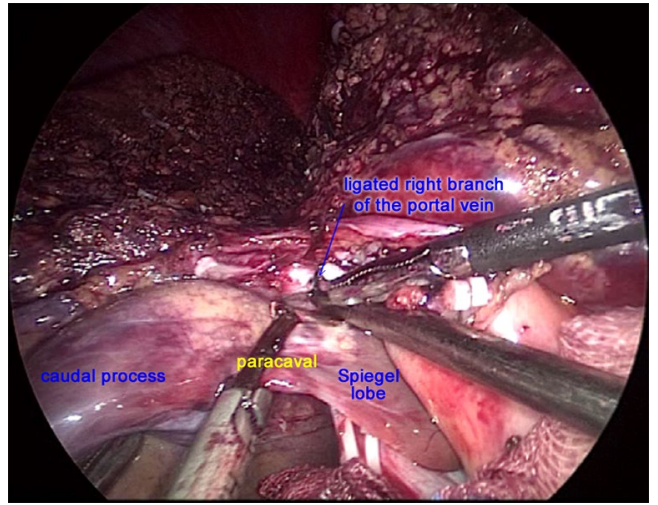

Figure 6 Dissection of the caudal lobe along the paracaval parenchyma.

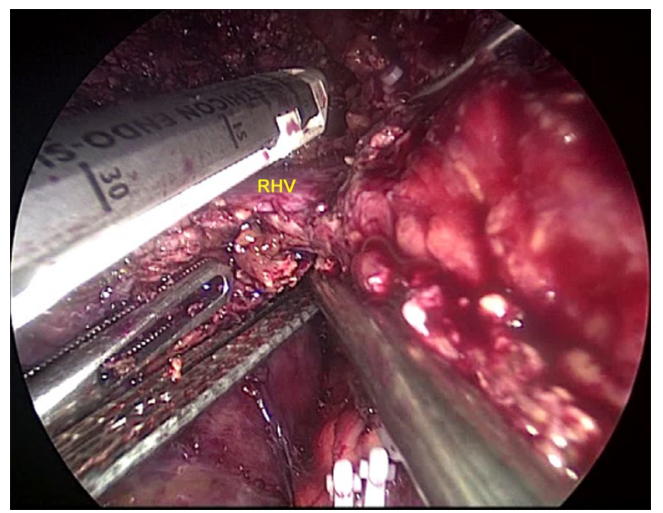

Figure 7 Dissection and ligation of the RHV with an Endo GIA stapler. RHV, right hepatic vein.

The procedure went well (Figure 8). The estimated blood loss was $200 \mathrm{~mL}$. Postoperative pathology suggested HCC of Edmondson Grade III and stage IIIA (pT3N0M0).

\section{Discussion}

We suggested anterior approach in laparoscopic right hepatectomy, which provide better exposure with a magnifying effect, especially at the surgical field around the IVC. The better exposure using the anterior approach could decrease the risk of injury during dissection of the first hepatic hilum before clamping. Laparoscopic hepatectomy has another advantage of reducing intraoperative hemorrhage, mainly from the hepatic vein, with the help of positive pneumoperitoneum pressure and properly controlled central venous pressure (7).

We used the technique of selective vascular clamping

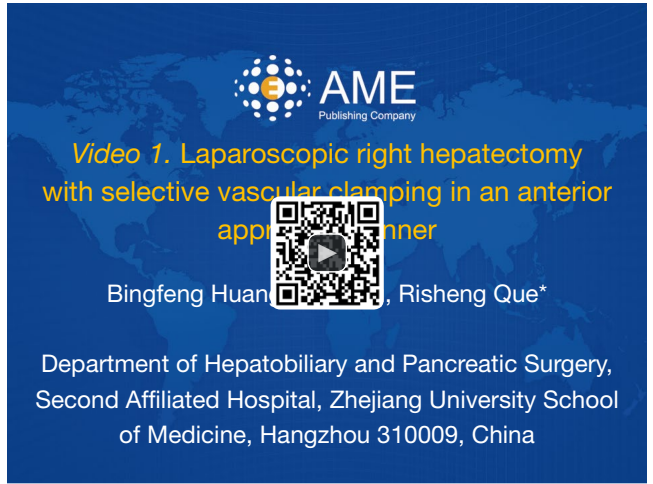

Figure 8 Laparoscopic right hepatectomy with selective vascular clamping in an anterior approach manner (9).

Available online: http://www.asvide.com/article/view/26848

to reduce the blood loss during parenchymal transection. An alternative clamping method is Pringle maneuver. The selective vascular clamping, with the theoretical advantage in anatomy, could achieve higher clamping efficacy and better postoperative outcomes (8), while increasing the surgical difficulties especially for large tumors or tumors near the root of the hepatic veins.

In addition, precise and gentle vascular dissection is also vital to the operation. The SHVs joining the IVC are short and fragile, which could sometimes contribute to a major hemorrhage when improperly dissected. Cautious dissection per vein or direct stapling of the SHVs should be applied intraoperatively to reduce the risk of massive hemorrhage and the rate of conversion.

In conclusion, the laparoscopic right hepatectomy with selective vascular clamping is feasible in an anterior approach, which is superior in providing clear exposure, reducing blood loss, and improving operative efficacy.

\section{Acknowledgments}

Dr. B Huang was awarded "The winner of AME Liver Surgery/Interventional Surgical Video National Championship". We thank Jianfeng Wang of the Second Affiliated Hospital, Zhejiang University School of Medicine for his help of video processing. We thank Dr. Sean RonnekleivKelly of the Johns Hopkins Hospital for his assistance.

Funding: This work was financially supported by the National Natural Science Foundation of China (grant numbers 81502026, 81530079) and the Zhejiang Provincial Natural Science Foundation (grant numbers LQ16H180002, LY18H160026). 


\section{Footnote}

Conflicts of Interest: All authors have completed the ICMJE uniform disclosure form (available at http://dx.doi. org/10.21037/tcr.2018.08.02). The authors have no conflicts of interest to declare.

Ethical Statement: The authors are accountable for all aspects of the work in ensuring that questions related to the accuracy or integrity of any part of the work are appropriately investigated and resolved. All procedures performed in study involving human participants were in accordance with the ethical standards of the institutional and/or national research committee(s) and with the Declaration of Helsinki (as revised in 2013). Written informed consent was obtained from the patient for publication of this manuscript and any accompanying images.

Open Access Statement: This is an Open Access article distributed in accordance with the Creative Commons Attribution-NonCommercial-NoDerivs 4.0 International License (CC BY-NC-ND 4.0), which permits the noncommercial replication and distribution of the article with the strict proviso that no changes or edits are made and the original work is properly cited (including links to both the formal publication through the relevant DOI and the license). See: https://creativecommons.org/licenses/by-nc-nd/4.0/.

\section{References}

1. Nguyen KT, Gamblin TC, Geller DA. World review

Cite this article as: Huang B, Hu Q, Que R. Laparoscopic right hepatectomy with selective vascular clamping in an anterior approach manner. Transl Cancer Res 2018;7(4):11681171. doi: $10.21037 /$ tcr.2018.08.02 of laparoscopic liver resection-2,804 patients. Ann Surg 2009;250:831-41.

2. Kanazawa A, Tsukamoto T, Shimizu S, et al. Laparoscopic Hepatectomy for Liver Cancer. Dig Dis 2015;33:691-8.

3. Zhang XL, Liu RF, Zhang D, et al. Laparoscopic versus open liver resection for colorectal liver metastases: A systematic review and meta-analysis of studies with propensity score-based analysis. Int J Surg 2017;44:191-203.

4. Han HS, Cho JY, Kaneko H, et al. Expert Panel Statement on Laparoscopic Living Donor Hepatectomy. Dig Surg 2018;35:284-8.

5. Kim JM, Kwon CH, Yoo H, et al. Which approach is preferred in left hepatocellular carcinoma? Laparoscopic versus open hepatectomy using propensity score matching. BMC Cancer 2018;18:668.

6. Chen K, Pan Y, Zhang B, et al. Laparoscopic versus Open Surgery for Hepatocellular Carcinoma: A Meta-Analysis of High-Quality Case-Matched Studies. Can J Gastroenterol Hepatol 2018;2018:1746895.

7. Wakabayashi G, Cherqui D, Geller DA, et al. Laparoscopic hepatectomy is theoretically better than open hepatectomy: preparing for the 2 nd International Consensus Conference on Laparoscopic Liver Resection. J Hepatobiliary Pancreat Sci 2014;21:723-31.

8. Zhang J, Lai EC, Zhou WP, et al. Selective hepatic vascular exclusion versus Pringle manoeuvre in liver resection for tumours encroaching on major hepatic veins. Br J Surg 2012;99:973-7.

9. Huang B, Hu Q, Que R. Laparoscopic right hepatectomy with selective vascular clamping in an anterior approach manner. Asvide 2018;5:730. Available online: http://www. asvide.com/article/view/26848 